\title{
Photostabilized LDPE Films with UV Absorber and HALS as Protection against the Light for Rosé Sparkling Wine
}

\author{
Kélen Cristofoli, Rosmary N. Brandalise and Mara Zeni*
}

Sciences and Technology Center, Caxias do Sul University, Caxias do Sul, Brazil

\begin{abstract}
Rose sparkling wines are photosensitive products thus subject to degradation by photo-oxidation over time when they are exposed on shelves. Consequently, its color gradually loses the most vibrant hues coupled with changes in aroma and flavor. An alternative to increase the shelf life of sparkling wines is the usage of light stabilizers, such as UV Absorbers (UVA) and Hindered Amine Light Stabilizers (HALS), substances that, when added to the packaging used for sparkling wines has the purpose of stabilizing the material, protecting the product. The purpose of this study was to evaluate the quality of rosé sparkling wines looking at the following properties: hue, colorimetric intensity, anthocyanins index and chemical characteristics using FTIR and visible-UV of Low Density Polyethylene films (LDPE) used as a protective layer for the exterior of colorless bottles. The stabilization system of LDPE films proposed in this study allowed the rosé sparkling wine to retain its chromatic characteristics longer, allowing for extensive periods of exposure on shelves, accounting for $60.4 \%$ reduction in the anthocyanins index for films with combined UVA/HALS, and $77.8 \%$ for films without photoprotection.
\end{abstract}

Keywords: Light stabilizers; Photo-oxidation; HALS; UVA; Rose sparkling wine

\section{Introduction}

The consumption of rosé sparkling wine in Brazil saw a significant increase as of 2007 (100.8\%) compared to 2006, while production rose to 883.248 million liters in 2010 [1]. Fermented wines are highly susceptible to oxidation given the amount of phenolic substances such as anthocyanins - present in fermented grapes. These substances, also referred to as polyphenols, make up a large number of beverages and foods and are relevant for their antioxidant action, preventing the formation of hydroperoxides, as well as for their organoleptic characteristics. The incidence of a hydroxylated aromatic chain where methyls were replaced in different positions (photosensitive substances) make these blends highly reactive when exposed to light sources during processing and/or storage of rosé sparkling wine $[2,3]$.

The chromatic aspect of rosé sparkling wines is very important since color is the first attribute to be noticed and, according to HernándezAgero [4], the hue and intensity of a color are visual features and therefore relate to a psychic sensation that may supply for knowledge on the wine quality and/or possible limitations. The energy irradiated by luminous or artificial sources, be it ultraviolet or perceptible, significantly affects the stability of rosé sparkling wine, in view of its capacity to activate decomposition by starting and then speeding up photochemical degradation reactions [3].

As rosé sparkling wines age, the color evolves from vibrant red to chestnut red, matching a decrease of monomeric anthocyanin content and an increase of polymeric pigments [5]. Wines with high color intensity tend to fade in a much shorter time than wines with less intense colors, because the molecules of the pigments tend to bond and form larger molecules, moving from a soluble state to the colloidal state and then to the insoluble state [6].

Wine bottles used so far are great containers to store these drinks, although the colorless bottles allow the light through them. The prolonged exposure to light, as in supermarket shelves, can damage the product which is inside and bring up an oxidation process which may result in a loss of quality and possible deterioration of the product [7].
The usage of stabilized LDPE films may be an option that would enable longer exposure time of rose sparkling wine, when colorless bottles are exposed to artificial light.

Light stabilizers are organic substances added to the polymer matrix during processing and their purpose is to prevent aging and slow down the degradation process, absorbing UV light and dissipating it as heat or defusing the results of photolysis [8]. Such additives act by disabling reactive factors of degradation or by consuming the products responsible for initiating reaction, the free radicals, preventing their spreading, through stabilization of UV light filtering through packaging and product [9-11].

Light stabilizers such as UV absorber (UVA) act in the absorption of UV radiation from the light energy dissipating it as thermal energy through chemical reactions [9], blocking the formation of free radicals and acting in the early stages of degradation [10] through a mechanism of reversible rearrangement formed by a ring chain that contains intra-molecular links of hydrogen of the bridge type and rearrange the ground state of the molecule from the absorber [11] (Figure 1). These substances have a high steric hindrance in the molecule and must be highly stable in order not to be consumed so fast in secondary reactions other than stabilization $[12,13]$.

Another class of light stabilizers widely used in polyolefins are HALS, Hindered Amine Light Stabilizers, i.e., the - NH groups are sterically hindered by the four methyl radicals in carbons adjacent to $-\mathrm{NH}$. The polymer is shielded through inhibition of free radicals formed by thermal and/or oxidative reactions, and the active specimen

*Corresponding author: Mara Zeni, Sciences and Technology Center, Caxias do Sul University, Caxias do Sul, Brazil, Tel: 95-070-970; E-mail: mzandrad@ucs.br

Received June 23, 2012; Accepted July 18, 2012; Published July 24, 2012

Citation: Cristofoli K, Brandalise RN, Zeni M (2012) Photostabilized LDPE Films with UV Absorber and HALS as Protection against the Light for Rosé Sparkling Wine. J Food Process Technol 3:166. doi:10.4172/2157-7110.1000166

Copyright: (c) 2012 Cristofoli K, et al. This is an open-access article distributed under the terms of the Creative Commons Attribution License, which permits unrestricted use, distribution, and reproduction in any medium, provided the original author and source are credited. 
is regenerated after each reaction cycle. Given its high efficiency it has been widely used in factories to help maintain brightness and flexibility of polymeric films in view of the capacity of abstracting peroxyl radicals $[8-9,14]$. This kind of light stabilizer acts by suppression of free radicals, where nitroxyl is formed by the action of light in the presence of oxygen and it is regenerated by the reaction of the end product with peroxyl radicals, according to the mechanism suggested by Kurumada [15] (Figure 2).

HALS acts by slowing but not eliminating the degradation process for any of these light stabilizers, by means of disabling free radicals or hydroperoxide decomposition. According to De Paoli [9], the most effective additives are those that can auto-recover themselves in a catalytic cycle. Besides acting as suppressors of excited states, most of these molecules disable excited carbonyl groups linked to the polymeric chain.

The light stabilizers can be consumed during the working life of the polymer (by chemical reaction) and/or their physical loss may occur depending on the chemical nature and geometry of the polymer, the solubility of the additive in the polymer, the environment in which it is inserted among others due to diffusion of the additive to the polymer surface during exposure and evaporation. The consumption and loss of stabilizers cause a faster aging process to the polymer than via thermooxidation or photo-oxidation $[11,14,16]$. Through copolymerization of the UV stabilizer with the polymer chain it is possible to achieve a significant reduction in extraction, volatility and migration of the UV stabilizer [17].

The ideal concentration to use photostabilizers in the polymer matrix will depend on the polymer used, process, application, stabilizer, and which type of product needs to be protected. High concentrations can lead to the formation of products that can act as pro-degraders, i.e., if a certain concentration level threshold is exceeded the effect is constant or can be reversed [9]. This study aimed at evaluating the influence of different concentrations of UV and HALS absorbers added to LDPE in the production of films used to protect light-sensitive beverages such as rosé sparkling wines. As a tool for comparison, the accelerated aging chamber was used to simulate environmental conditions akin to "time on display" for the content of sparkling wine bottles. Finally, the purpose of the study targets maximization of stability for rosé sparkling wine exposed to light in an attempt to simulate the exposure conditions to which the product may be subjected on supermarket shelves, which could trigger photo-oxidation processes. Chromatic characteristics such as color hue, colorimetric intensity and anthocyanins index of the rosé sparkling wine exposed in the chamber as well as analyses of the chemical properties of polyethylene films exposed to degradation were taken into exam.

\section{Materials and Methods}

\section{Materials}

The LDPE is from Braskem Co. (film blowing grade) with a melt index of $2.7 \mathrm{~g} / 10 \mathrm{~min}$. The light stabilizers were supplied by Ciba Specialty Chemicals Inc. (Table 1 ).

\section{Film preparation}

HALS and UVA were added to LDPE in a single screw blow extruder from Seibt, model ES35F, diameter $35 \mathrm{~mm}$, L/D ratio=32, velocity $43 \mathrm{rpm}$; diameter: $40 \mathrm{~mm}$; with processing temperature profile of $110,150,150,150$ and $160^{\circ} \mathrm{C}$.

Compositions, conditions of exposure to degradation and codification of the additives used individually or in association, are shown in (Table 2). The films produced were $40 \mu \mathrm{m} \pm 1 \mu \mathrm{m}$ thick.

The samples were placed in a UV aging chamber, Comexim Matérias Primas Ind.Com.Ltda, with 8 fluorescent mercury vapor lamps, model UVBTL 40W/12, Philips, with $\lambda=313 \mathrm{~nm}$ light intensity, interspersing sessions of exposure to the condensation atmosphere $\left(40^{\circ} \mathrm{C}\right)$ and UV radiation $\left(60^{\circ} \mathrm{C}\right)$, every four hours and ending the cycle every 8 hours.

\section{FTIR-spectroscopy}

A Thermo Scientific Nicolet ${ }^{\mathrm{m}}$, model IS $\mathrm{S}^{\mathrm{ma}} 10$, was used for samples in the form of films and for the pure additives, $\mathrm{KBr}$ pellets were used. The spectra were taken as a resolution of $4 \mathrm{~cm}^{-1}$ in the range from 4000 to $400 \mathrm{~cm}^{-1}$.

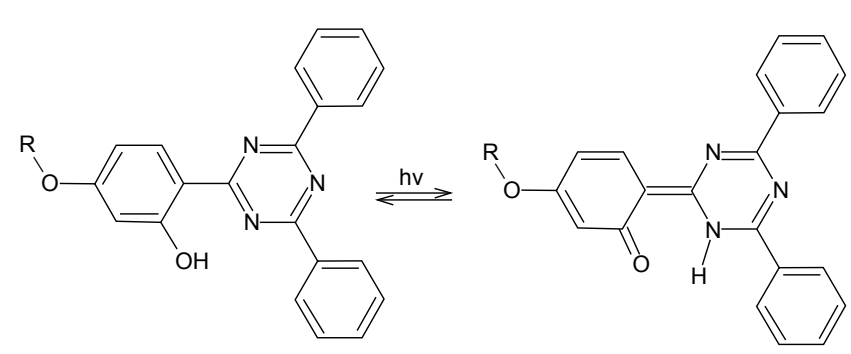

Figure 1: Proposed action mechanism UV absorber [9].

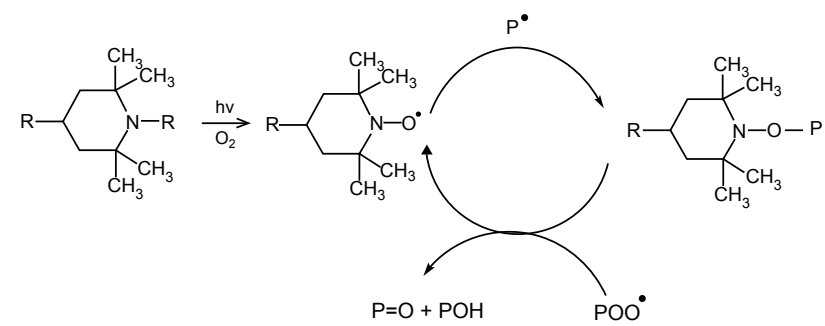

Figure 2: Proposed action mechanism HALS [15].

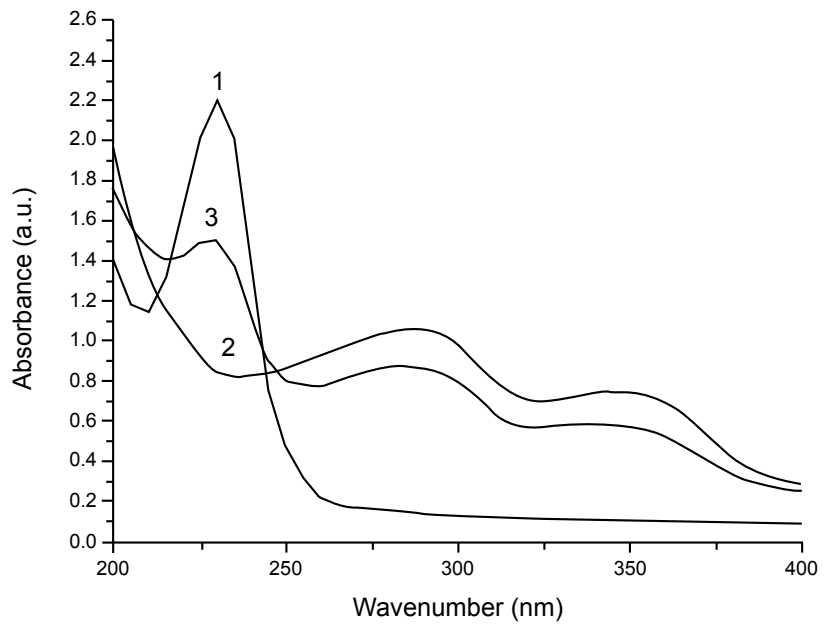

Figure 3: UV/Vis spectra of the samples before exposure: (1) PEH; (2) PEA e (3) PEAH-2. 
Citation: Cristofoli K, Brandalise RN, Zeni M (2012) Photostabilized LDPE Films with UV Absorber and HALS as Protection against the Light for Rosé Sparkling Wine. J Food Process Technol 3:166. doi:10.4172/2157-7110.1000166

Page 3 of 7

\section{UV-Vis spectrophotometry}

Films: The LDPE films were characterized in a UV/Vis spectrophotometer, Beckman model DU-530. The readings were taken with a resolution of $5 \mathrm{~nm}$ in the wavelength range between 400 and $200 \mathrm{~nm}$.

Sparkling wines: Analyses of the colorimetric intensity, shade and index of anthocyanins were performed immediately after the withdrawal of samples from exposure to accelerated aging, and centrifuged for $5 \mathrm{~min}$ to precipitate the coloring matter in suspension, at a velocity of $5000 \mathrm{rpm}$, using a Bio Eng BE-5000 centrifuge.

Colorimetric intensity (ICM): The quantification of colorimetric intensity levels was determined by the method described by the International Organization of Vine and Wine (OIV) [18], at the sum absorbances of $420 \mathrm{~nm}$ and $520 \mathrm{~nm}$, measured in glass cells with an optical path equal to $1 \mathrm{~cm}$.

Shade: The quantification of the rosé sparkling wine shade was performed according to the OIV [18] by the ratio between the absorbencies of $420 \mathrm{~nm}$ and $520 \mathrm{~nm}$.

\section{Anthocyanins Index}

The anthocyanins were determined based on the difference in color compared to their $\mathrm{pH}$, according to the following method: five $\mathrm{mL}$ of sample are transferred to a $50 \mathrm{~mL}$ volumetric flask which is then filled with an ethanol/hydrochloric solution. Wait 30 minutes for the resulting solution to react and take a reading at a $540 \mathrm{~nm}$ wavelength, with ethanol/hydrochloric solution as a blank [19]. The result is obtained from Eq. 1.

$$
\mathrm{AI}=\mathrm{ABS} \times 20 \mathrm{x}
$$

\section{Results and Discussion}

\section{Characterization of films}

Figure 3 shows the maximum absorbance of the films with additives, using the UV/Vis spectrophotometry technique, in order to verify the incorporation of additives in the films after extrusion. The HALS showed only a single maximum absorption peak at $230 \mathrm{~nm}$, while the LDPE with UV absorber showed two absorption maxima, one at $345 \mathrm{~nm}$ and another at $285 \mathrm{~nm}$, characteristic of this product (Figure 3).

The photostability of a wide variety of polymers can be improved by combining two or more light stabilizers. De Paoli [9], Avar and Bechtold [20] reported that for a good result it is ideal to use a HALS and UV absorber together in order to increase polymer durability and the polymer protection that this gives some other product. According to Basfar et al. [21], the combination of HALS with UV absorber reinforces the light stability of LDPE. In this sense, the combination of HALS and UV absorber in the polymer resulted in the appearance of three absorbance peaks in the ultraviolet corresponding to each of these additives (Figure 3 ).

The chemical changes in the polymer structure in relation to the appearance of carbonyl group $\left(1700 \mathrm{~cm}^{-1}\right)$ and vinyl group (908 $\mathrm{cm}^{-1}$ ) absorbance were investigated by FTIR spectroscopy, as well as the characteristic band of additives for the LDPE additive (Figure 4). This allows showing the appearance of bands corresponding to characteristic groups in polymer degradation without additives before and after exposure to accelerated aging in the PE sample.

\begin{tabular}{l|l|l|}
\hline Code & Chemical name & Trademark \\
\hline UVA & 2-(4,6-diphenyl-1,3,5-triazin-2-yl)-5-[(hexyl)oxy]-phenol & Tinuvin 1577 \\
\hline HALS & $\begin{array}{l}\text { 1,6-hexanediamine, N,N'-bis(2,2,6,6-tetrametthyl-4-piperidinyl)- polymer with 2,3,6-trichlor-1,3,5-triazine, reaction products with, N-butyl-1- } \\
\text { butanamine and N-butyl-2,2,6,6-tetramethyl-4-piperidinamine }\end{array}$ & \begin{tabular}{l} 
Chimassorb 2020 \\
\hline
\end{tabular}
\end{tabular}

Table 1: Light stabilizers used.

\begin{tabular}{|c|c|}
\hline Sample & Description \\
\hline PE & LDPE \\
\hline PEAH-1 & LDPE with $0.5 \%$ of UV absorber and $0.75 \%$ of HALS \\
\hline PEAH-2 & LDPE with $1.0 \%$ of UV absorber and $0.75 \%$ of HALS \\
\hline PEAH-3 & LDPE with $1.5 \%$ of UV absorber and $0.75 \%$ of HALS \\
\hline PEA & LDPE with $0.8 \%$ of UV absorber \\
\hline $\mathrm{PEH}$ & LDPE with $0.75 \%$ of HALS \\
\hline E-PE & Sparkling wine with LDPE film \\
\hline E-PEAH-1 & Sparkling wine with LDPE film containing $0.5 \%$ of UV absorber and $0.75 \%$ of HALS \\
\hline E-PEAH-2 & Sparkling wine with LDPE film containing $1.0 \%$ of UV absorber and $0.75 \%$ of HALS \\
\hline E-PEAH-3 & Sparkling wine with LDPE film containing $1.5 \%$ of UV absorber and $0.75 \%$ of HALS \\
\hline E-PEA & Sparkling wine with LDPE film containing $0.8 \%$ of UV absorber \\
\hline E-PEH & Sparkling wine with LDPE film containing $0.75 \%$ of HALS \\
\hline
\end{tabular}

* \% (wt). ${ }^{* *}$ All samples were subjected to exposure in an accelerated aging chamber for 72, 168, 264, 360 and 912 hours

Table 2: Composition and conditions of the samples prepared for accelerated aging test.

\begin{tabular}{|c|c|c|c|c|c|c|}
\hline Time (h) & E-PE & E-PEAH-1 & E-PEAH-2 & E-PEAH-3 & E-PEA & E-PEH \\
\hline 0 & $1.33 \pm 0,036$ & $1.33 \pm 0,036$ & $1.33 \pm 0,036$ & $1.33 \pm 0,036$ & $1.33 \pm 0,036$ & $1.33 \pm 0,036$ \\
\hline 72 & $1.37 \pm 0,01$ & $1.36 \pm 0,09$ & $1.33 \pm 0,065$ & $1.30 \pm 0,014$ & $1.39 \pm 0,048$ & $1.38 \pm 0,022$ \\
\hline 168 & $2.31 \pm 0,014$ & $2.09 \pm 0,08$ & $1.7 \pm 0,036$ & $1.48 \pm 0,01$ & $1.67 \pm 0,037$ & $1.64 \pm 0,018$ \\
\hline 264 & $2.73 \pm 0,022$ & $2.82 \pm 0,28$ & $2.23 \pm 0,024$ & $1.58 \pm 0,045$ & $2.07 \pm 0,01$ & $1.86 \pm 0,021$ \\
\hline 360 & $4.65 \pm 0,03$ & $4.90 \pm 0,13$ & $2.62 \pm 0,03$ & $2.18 \pm 0,017$ & $2.27 \pm 0,011$ & $2.15 \pm 0,04$ \\
\hline 912 & $8.40 \pm 0,15$ & $6.60 \pm 0,11$ & $3.04 \pm 0,03$ & $2.80 \pm 0,039$ & $5.01 \pm 0,02$ & $4.24 \pm 0,042$ \\
\hline
\end{tabular}

Table 3: Correlation of the shade of sparkling wine for each sample according to the period of exposure to UV ageing. 
The intensity of the bands at 1713 and $1731 \mathrm{~cm}^{-1}$ increased with exposure time (0-912 h) for non-stabilized LDPE films. According to Kaci et al. [22] this increase was ascribed to photo-oxidative reactions with the formation of carbonyl groups $(-\mathrm{C}=\mathrm{O})$. At $1713 \mathrm{~cm}^{-1}$, they corresponded to acid carbonyl and at $1731 \mathrm{~cm}^{-1}$ to ketone carbonyl. Hydroperoxides are the main compounds produced from photooxidation mechanisms of polyethylene. Their decomposition can lead to the formation of several oxidized products such as carboxylic acids, alcohols, ketones, esters and vinyl [23,24]. The occurrence of absorption in the $1640 \mathrm{~cm}^{-1}$ band is also observed, and concerns the deformation of the group $(-\mathrm{C}=\mathrm{C}-)$ of double bonds, and in $908 \mathrm{~cm}^{-1}$ corresponds to angular deformation of the group $\left(\mathrm{H}_{2} \mathrm{C}=\mathrm{C}-\right)$ of terminal vinyl double bonds, resulting from Norrish II type reactions [25].

For films stabilized with HALS (PEH sample) there were no bands in the 1700 and $908 \mathrm{~cm}^{-1}$ range for the same period of exposure. These bands characterize the degradation of polyethylene (Figure 5). However, the band at $1534 \mathrm{~cm}^{-1}$, corresponding to the amine groups of HALS, decreased during the exposure. This result suggests that HALS offers significant protection for the LDPE film because it stabilizes the photo-oxidative process responsible for the formation of carbonyl and vinyl groups. According to Kaci et al. [22], this can be attributed to the deactivation of ketone carbonyl excited states by HALS.

The decrease in the absorption band at $1534 \mathrm{~cm}^{-1}$ is due to several factors: additive consumption during the exposure period, stabilizing the free radicals of degradation [26], or due to loss of additive by diffusion to the polymer surface, and also by chemical and degradation reactions, by evaporation or by leaching $[27,28]$.

When the light stabilizer used was a UV absorber at a concentration of $0.8 \%(\mathrm{w} / \mathrm{w})$ in the LDPE film (PEA), an effect contrary to the HALS (PEH) was observed (Figure 6). It is noted that there was no effective protection of UV absorber in the PE film, since bands at 1713 and 1731 $\mathrm{cm}^{-1}$ and $908 \mathrm{~cm}^{-1}$, were shown, especially beginning at 264 hours of exposure. Kaci et al. [22] reported that the formation of vinyl groups was directly associated with the increase of carbonyl groups.

The spectra in infrared for the samples that were additivated with different combinations of the two classes of light stabilizers are shown in Figure 7.

In the three combinations studied, PEAH-1, PEAH-2, and PEAH3 , there was no banding in the range of $1700 \mathrm{~cm}^{-1}$ and $908 \mathrm{~cm}^{-1}$ characteristic of degradation of LDPE, as it was possible to observe the presence of bands characteristic of additives in 1543 and $1512 \mathrm{~cm}^{-1}$ for the duration of exposure to UV aging.

\section{Characterization of Sparkling Wines}

The color of rose sparkling wine is the first factor that is changed in accordance with the incidence of light. Thus, (Figure 8) shows the change in the colorimetric intensity of the liquid as a function of time of exposure in a UV chamber. The E-PE sample showed the value of intensity of absorption, at a wavelength of $420 \mathrm{~nm}$, of 1.428 , higher than the other samples during equal period of exposure (Figure 8a). The increased absorption in this range is related to the increase of yellow pigments in the sparkling wine and is caused by the polymerization of tannins and the combination of tannins with anthocyanins [29].

At a $520 \mathrm{~nm}$ wavelength all samples showed decreased absorption during the period of exposure, except for sample E-PEAH-3 in which increased absorption was seen up to 264 hours. After this period, it decreased, but the decrease presented a higher intensity of absorption
(0.424) compared to the others (Figure 8b). The decreased intensity of absorption observed in the samples was attributed to oxidative degradation of anthocyanins, whereas the increase in absorption observed in sample E-PEAH-3 may be related to the colorless molecules (polymerized flavones) which are formed during oxidation and, sometimes are colored by oxidation $\left(\mathrm{A}_{520}\right.$ increases) [30]. According to Glories [29], absorption at $520 \mathrm{~nm}$ refers to the tendency to the development of a reddish color and greater amounts of anthocyanins in the product. Thus, the sample E-PEAH-3 showed more red pigments after the exposure period.

Color intensity varies according to the grape varieties used and their concentrations, since rosé sparkling wine can be made from a mixture of red and white wine. Table 3 shows the different shade values

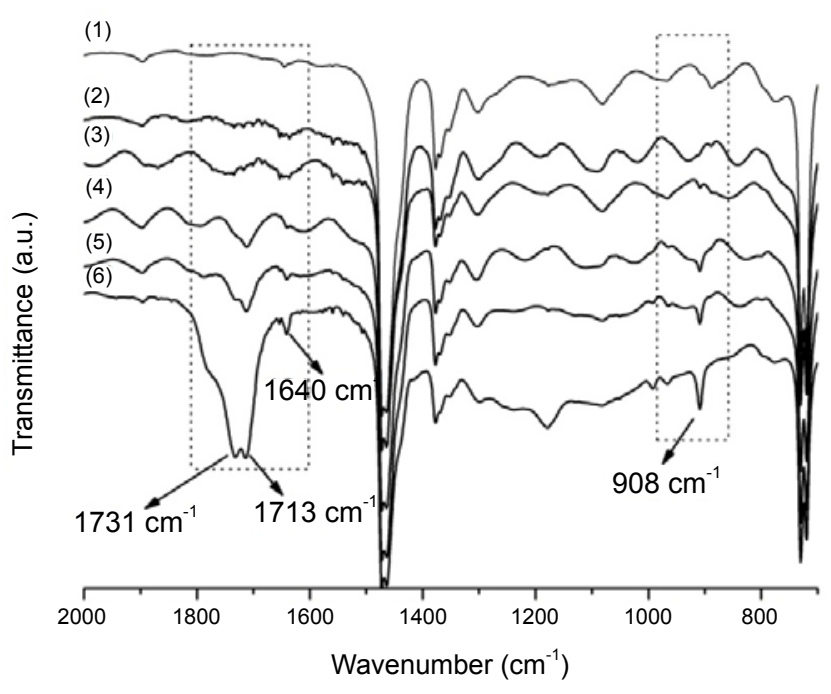

Figure 4: FTIR spectrum of LDPE samples: (1) before exposure; (2) $72 \mathrm{~h}$; (3) 168 h; (4) 264 h; (5) 360 h; (6) 912 h, after UV exposure.

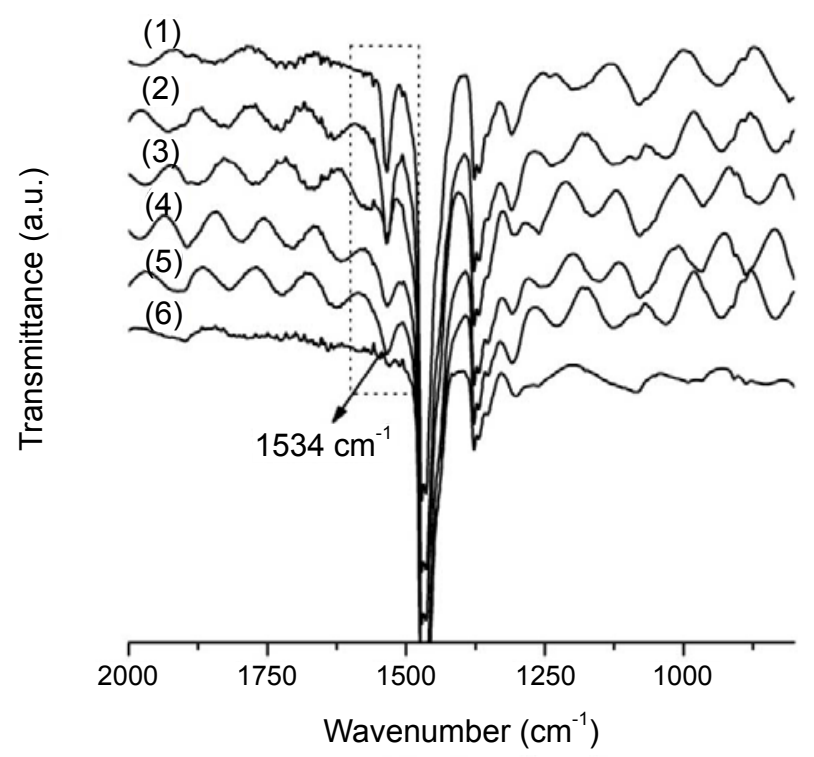

Figure 5: FTIR spectrum of PEH samples: (1) before exposure; (2) $72 \mathrm{~h}$; (3) 168 h; (4) 264 h; (5) 360 h; (6) 912 h, after UV exposure. 


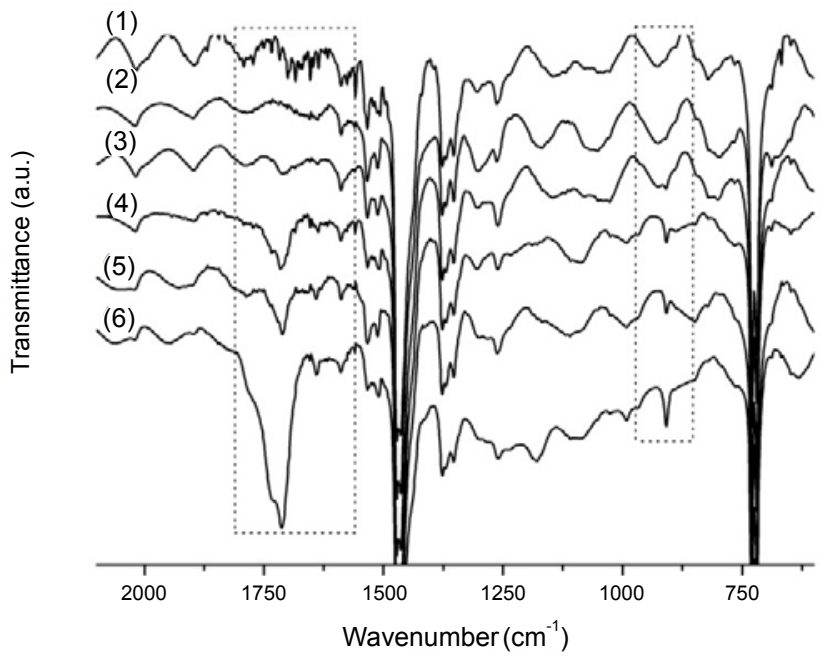

Figure 6: FTIR spectrum of PEA, before and after exposure. (1) before exposure; (2) 72 h; (3) 168 h; (4) 264 h; (5) 360 h; (6) 912 h after exposure.

obtained during the period of exposure for light stabilized and nonadditivated films. Sample E-PE show the highest shade values during all periods of exposure, whereas sample E-PEAH-3 showed the lowest shade values in the same period. Samples E-PEA and E-PEH with separate additives, presented intermediate values but lower than when the light stabilizers were used together. According to Ribereau-Gayon et al. [31] young wines have shades that vary from 0.5 to 0.7 , tending to increase during aging.

When analyzed in relation to the anthocyanin index, (Figure 9), the rosé sparkling wine showed the smallest change for sample E-PEAH-3 during the exposure period. During the maximum period of $912 \mathrm{~h}$ its index was 11.4 while for the sample without light stabilizers this value was 6.4. Exposure to light promoted a decrease of $78 \%$ of the stability of anthocyanins in samples that did not have photoprotection. For sample E-PEAH-3 this decrease was approximately $60 \%$, and in samples with light stabilizers the decrease was $76 \%(\mathrm{E}-\mathrm{PEH})$ and $71.5 \%$ (E-PEA). This suggests that the samples of sparkling wine protected by LDPE films with a combination of light stabilizers supplied greater protection to the product than the LDPE film which was not additivated because it maintains a higher anthocyanin index. Gris [32] found that the light degraded the anthocyanins of grape varieties such as Cabernet Sauvignon, significantly reducing their half life by about $50 \%$, and found higher half-life values of the anthocyanins in this cultivar in the absence of light and presence of nitrogen, amount of 225 hours (approximately 9 days) when compared to its control sample.

\section{Conclusion}

The present study offered an analysis of the effects of two different types of photostabilizers used in PEBD that are employed as protection for rose sparkling wines bottled in colorless containers exposed to accelerated ageing process UVB as well as of the effect of different concentration levels of these photostabilizers. Considering the results of the study it is possible to draw the following conclusions:

PEBD films without additives used as protection for rose sparkling wines showed evidence of degradation after different periods of exposure in the UV accelerated ageing chamber. Whenever the films were stabilized with HALS, they showed stability against degradation
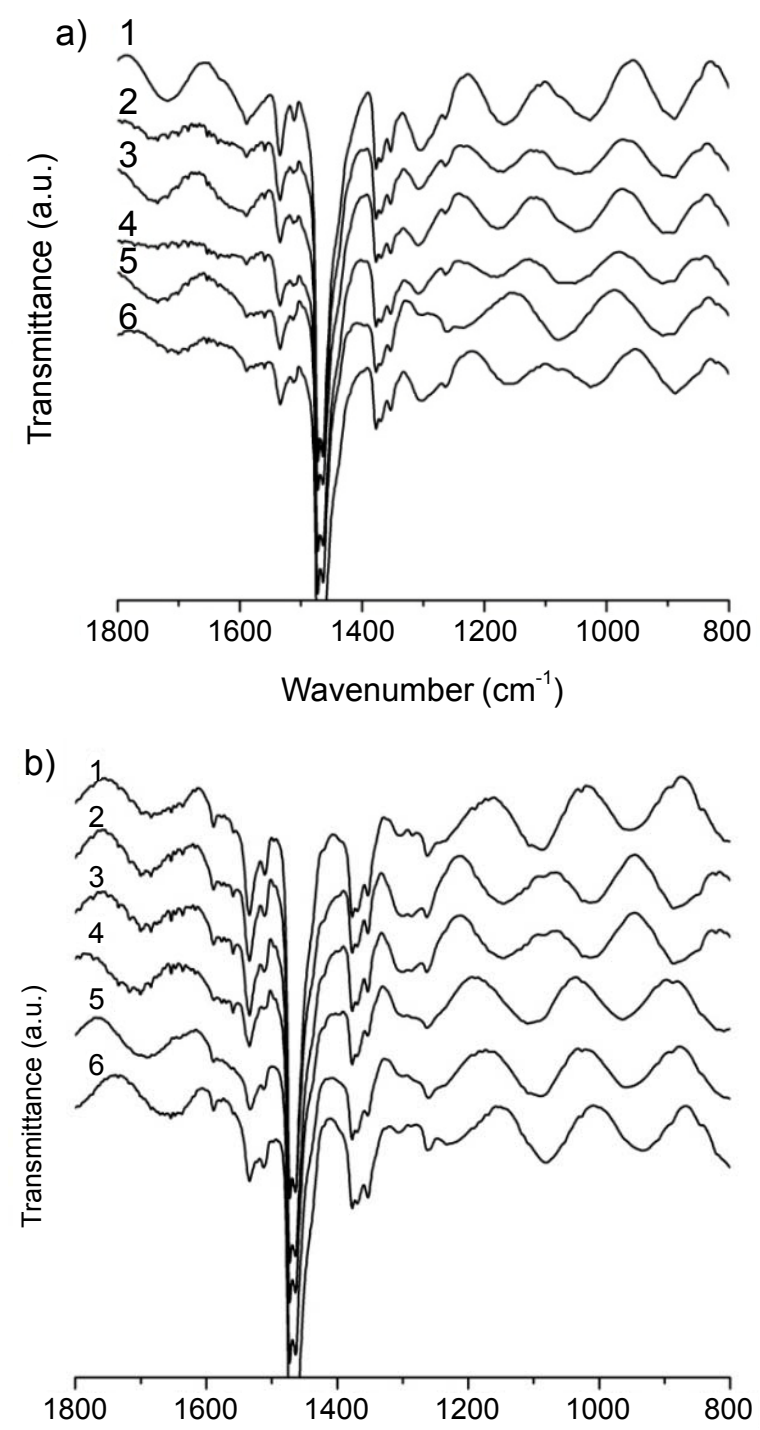

Wavenumber $\left(\mathrm{cm}^{-1}\right)$

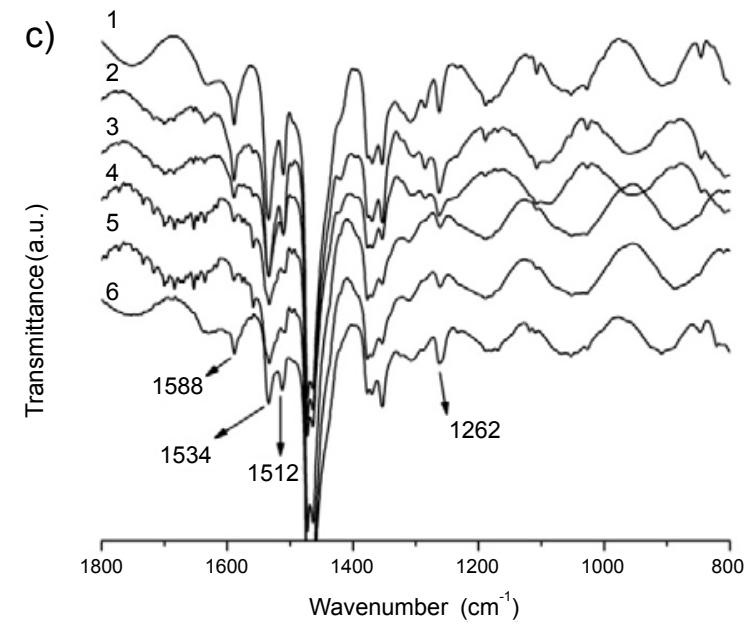

Figure 7: FTIR spectrum of samples: a) PEAH-1; b) PEAH-2; c) PEAH-3, according to the exposure period: (1) before exposure; (2) $72 \mathrm{~h}$; (3) $168 \mathrm{~h}$; (4) $264 \mathrm{~h}$; (5) $360 \mathrm{~h}$; (6) $912 \mathrm{~h}$ of exposure. 

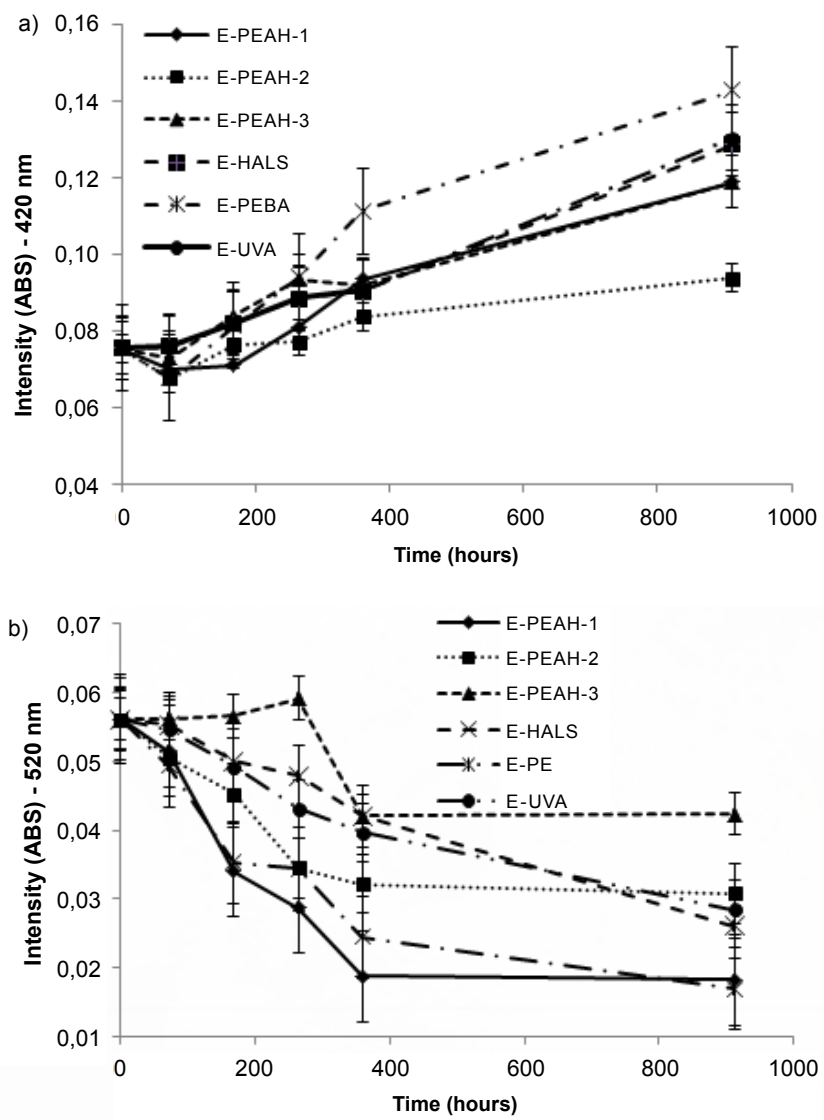

Figure 8: Intensity of absorption of sparkling wine according to the time of exposure to UV ageing; a) a wavelength of $420 \mathrm{~nm}$, b) a $520 \mathrm{~nm}$.

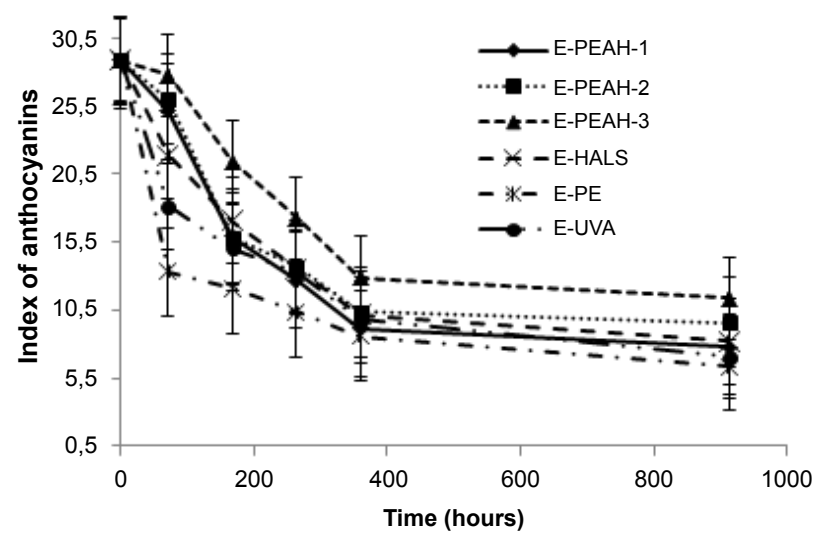

Figure 9: Index of anthocyanin variation of sparkling wine during the period of exposure to UV ageing.

when considering an exposure time of 360 hours. After this threshold the HALS amine group level decreased. The UV absorber was not effective in stabilizing LDPE films and evident signs of degradation began as of 264 hours of exposure, also visible as absorbance intensity at $420 \mathrm{~nm}$ of rose sparkling wine and increase in absorbance at $520 \mathrm{~nm}$. The combined stabilizers, instead, used for LDPE films were effective throughout the entire period of exposure of this study.
Rose sparkling wine protected by means of LDPE without use of stabilizers showed significant chromatic changes. With the use of HALS and the UV absorber less changes were observed, predominantly in the anthocyanin index where a reduction of $60.4 \%$ in the PEAH3 sample was observed, while a $77.8 \%$ reduction was observed in the sample PE-film without any photostabilizer for the same duration of exposure.

The stabilization system suggested in this study allowed the rose sparkling wines to maintain their chromatic characteristics, increasing the "display life" of the wines from 6 to approximately 12 months insofar as protected with LDPE films where additives of combined HALS and UVA were added in the proportions reflected in the PEAH-3 sample, while the use of simply UVA in PEBD films is not recommended.

\section{Acknowledgements}

The authors thank at the UCS, CNPq and Salton Winery Co. for providing the sparkling wine.

\section{References}

1. IBRAVIN-Instituto Brasileiro da Uva e do Vinho (2011) Cadastro Vinícola Acessed.

2. Cabrita MJ, Silva JR, Laureano O (2003) OS compostos polifenólicos das uvas e dos vinhos. I Seminário Internacional de Vitivinicultura. Ensenada.

3. Kuskoski EM, Asuero AG, Garcia-Parilla MC, Troncoso AM, Fett R (2004) Actividad antioxidante de pigmentos antociánicos. Ciência e Tecnologia de Alimentos 24: 691-693.

4. Hernández-Agero APO, Garcia de la Peña ME, Torogos JH, Priego PT, Rozalen PN, et al. (1993) Contribucíon al studio del color de los vinos españoles. Vitivinicultura 11012: 52-56.

5. Somers TC (1976) Pigment development during ripening of the grape. Vitis 14: $269-277$

6. Freitas DM (2006) Variação dos compostos fenólicos e de cor dos vinhos de uvas (Vitis vinífera) tintas em diferentes ambientes. Tese Universidade de Santa Maria.

7. de Oliveira Alves, Arruda CS, Ogliari PJ, Meinert EM, Teixeira E, et al. (2005) Efecto de La adición del absorbedor UV (Tinuvin 234) sobre la calidad de aceite de soja em envases de polietileno tereftalato (PET). Grazas Y Aceites 56: $245-253$

8. Pas SJ, Tuomisto F, Saarinen K, Ammala A, Turney TW, et al. (2007) Stabilise distribution and efficiency examined by depth profiling polypropylene using a pósitron beam. Surface Science 601: 5750-5756.

9. De Paoli MA (2009) Degradação e Estabilização de Polímeros. $1^{a}$ Ed. São Paulo: Artliber.

10. Coltro L, Buratin Ana EP (2004) Garrafas de Pet para óleo comestívelAvaliação da barreira à luz. Polímeros Ciência e Tecnologia 14: 206-211.

11. Scully AD, Ghiggino KP (1995) Ultrafast processes in photoirradiated polymers and polymer additives. In: Allen, N.S. et al. Current Trends in Polymer Photochemistry. New York: Ellis Horwood.

12. Gugumus $F(2002)$ Possibilities and limits of synergism with light stabilizers in polyolefins 2. UV absorbers in polyolefins. Polymer Degradation and Stability 75: $309-320$

13. Dobashi Y, Ohkatsu Y (2008) Dependence of ultraviolet absorbers' performance on ultraviolet wavelength. Polymer Degradation and Stability 93: 436-447.

14. Haider N, Karlsson S (2001) Loss of Chimassorb 944 from LDPE and identification of additive degradation products after exposure to water, air and compost. Polymer Degradation and Stability 74: 103-112

15. Kurumada T, Ohsawa H, Yamazaki T (1987) Synergism of Hindered Amine Light Stabilizers and UV-Absorbers. Polymer Degradation and Stability 19 : 263-272.

16. Gerlock JL, Tang W, Dearth MA, Korniski TJ (1995) Reaction of benzotriazole ultraviolet light absorbers with free radicals. Polymer Degradation and Stability 48: $121-130$ 
Citation: Cristofoli K, Brandalise RN, Zeni M (2012) Photostabilized LDPE Films with UV Absorber and HALS as Protection against the Light for Rosé Sparkling Wine. J Food Process Technol 3:166. doi:10.4172/2157-7110.1000166

17. Zhao Y, Dan Y (2007) Synthesis and characterization of a polymerizable benzophenone derivative and its application in styrenic polymers as UVstabilizer. European Polymer Journal 43: 4541-4551.

18. International Organisation of Vine and Wine (OIV) (2008) Compendium of International Methods of Wine and Must Analysis. Paris: O.I.V, Edition.

19. Rizzon LA (2010) Metodologia para análise de vinho. Bento Gonçalves: Embrapa-CNPUV.

20. Ávar L, Bechtold K (1999) Studies on the interaction of photoreactive light stabilizers and UV-absorbers. Progress in Organic Coatings 35: 11-17.

21. Basfar AA, Ali KMI, Mofti SM (2003) UV stability and radiation-crosslinking of linear low density polyethylene and low density polyethylene for greenhouse applications. Polymer Degradation and Stability 82: 229-234.

22. Kaci M, Sadoun T, Cimmino S (2000) HALS stabilization of LDPE films used in agricultural applications. Macromolecular Materials and Engineering 278: 36-42.

23. Tidjani A (2000) Comparison of formation of oxidation products during photooxidation of linear low density polyethylene under different natural and accelerated weathering conditions. Polymer Degradation and Stability 68: 465469.

24. Gulmine JV, Janissek PR, Heise HM, Akcelrud L (2003) Degradation profile of polyethylene after artificial accelerated weathering. Polymer Degradation and Stability 79: 385-397.
25. Albertsson AC, Andersson SO, Karlsson S (1987) The Mechanism of Biodegradation of Polyethylene. Polymer Degradation and Stability 18: 73-87.

26. Richaud E, Fayolle B, Verdu J (2011) Polypropylene stabilization by hindered phenols-kinetic aspects. Polymer Degradation and Stability 96: 1-11.

27. Scoponi M, Cimmino S, Kaci M (2000) Photo-stabilization mechanism unde natural weathering and accelerated photo-oxidative conditions of LDPE films for agricultural applications. Polymer 41: 7969-7980.

28. Bell B, Beyer DE, Maecker NL, Papenfus RP, Priddy DB (1994) Permanence of polymer stabilizers in hostile environments. Journal of Applied Polymer Science 54: 1605-1612.

29. Glories Y (1984) La couleur des vins rouges. $1^{\text {a }}$ partie: Les equilibres des anthocyanes et des tannins. Connaiss. Vigne Vin France 18: 195-217.

30. Glories Y La (1984) Couleur des vins rouges. $2^{\mathrm{a}}$ partie: mesure, origine et interpretation. Connaiss. Vigne Vin France 18: 253-271.

31. Ribereau-Gayon P, Glories Y, Maujean A, Dubourdieu D (2003) Tratado de enologia: química Del vino, estabilización y tratamientos. Buenos Aires: Hemisferio Sur 2.

32. Gris EF (2005) Caffeic acid copigmentation of anthocyanins from Cabernet Sauvignon grape extracts in model systems. Food Chemistry. 